\title{
BMJ Open Temporal relationship between hospital admissions for pneumonia and weather conditions in Shanghai, China: a time-series analysis
}

\author{
Yuan Liu, ${ }^{1}$ Haidong Kan, ${ }^{1,2}$ Jianming $\mathrm{Xu},{ }^{3,4}$ David Rogers, ${ }^{5}$ Li Peng, ${ }^{3,4}$ \\ Xiaofang Ye, ${ }^{3,4}$ Renjie Chen, ${ }^{1}$ Yue Zhang, ${ }^{1}$ Weibing Wang ${ }^{1,2}$
}

To cite: Liu Y, Kan $\mathrm{H}, \mathrm{Xu}$ J, et al. Temporal relationship between hospital admissions for pneumonia and weather conditions in Shanghai, China: a time-series analysis BMJ Open 2014;4:e004961. doi:10.1136/bmjopen-2014004961

- Prepublication history and additional material is available. To view please visit the journal (http://dx.doi.org/ 10.1136/bmjopen-2014004961).

Received 14 February 2014 Revised 10 June 2014 Accepted 13 June 2014

CrossMark

For numbered affiliations see end of article.

Correspondence to Professor Weibing Wang; wwb@fudan.edu.cn

\section{ABSTRACT}

Objectives: To explore the association between weather conditions and hospital admissions for pneumonia in Shanghai.

Design: A time-series analysis was performed for a period of 4 years ( January 2008-December 2011). A generalised additive model was used to calculate the relative risks.

Setting: Shanghai, China.

Participants: All daily hospital admissions for pneumonia were obtained from the Shanghai health insurance system between 1 January 2008 and 31 December 2011 ( $n=99$ 403).

Results: The relationship between the mean temperature and pneumonia hospital admissions followed a V-shaped curve, with an optimum temperature (OT) at $13^{\circ} \mathrm{C}$. When the mean temperature was below the $0 \mathrm{~T}$, a $1^{\circ} \mathrm{C}$ decrease corresponded to a $4.88 \%(95 \% \mathrm{Cl} 2.71 \%$ to $7.09 \%)$ and $5.34 \%(95 \% \mathrm{Cl}$ $2.04 \%$ to $8.74 \%$ ) increase in pneumonia hospital admissions in lag 4 using a single-day lag structure and lag 0-7 using a multiday lag structure. When the mean temperature $\geq 0 T$, no adverse effects from the temperature on pneumonia hospital admissions were found. The magnitude of the effects of temperature varied across gender and age groups. Hospitalisations for pneumonia increased by $15.99 \%$ ( $95 \% \mathrm{Cl} 0.06 \%$ to $34.46 \%)$ in the cold period.

Conclusions: Cold temperature may be one of the important risk factors for pneumonia hospitalisations. Prevention programmes are needed to reduce the impact of cold temperature on pneumonia hospitalisations such as developing a weather warning system within a wide public health context.

\section{BACKGROUND}

Despite the availability of safe and effective antibiotics and vaccines for treatment and prevention, pneumonia is still a leading cause of death worldwide. ${ }^{12}$ Pneumonia, in general lower respiratory tract infections, accounts for $6.6 \%$ of all deaths globally. ${ }^{3}$ In

\section{Strengths and limitations of this study}

Generalised additive models and two different lag structures were developed to explore the possible interaction between meteorological factors and hospital admissions for pneumonia.

- We used the available outdoor monitoring data of ambient meteorological factors derived from a monitoring station rather than measures of personal exposure. This is expected to result in exposure misclassification.

adults, the incidences varied between 1.6 and $11 / 1000$ adults in different countries, with hospitalisation proportions ranging from $40 \%$ to $60 \%$. $^{4}$ China is estimated to have 2.5 million pneumonia cases annually, of which $5 \%$ die from pneumonia-related diseases. ${ }^{56}$

Climate change is potentially the largest global threat to human health. ${ }^{7}$ In recent years, the association between meteorological factors and respiratory diseases has been observed extensively. Temperature has been reported to lead not only to direct deaths and illnesses and also to the aggravation of respiratory diseases. ${ }^{8}{ }^{9}$ Several studies have emphasised the relationships between temperature and daily respiratory deaths. ${ }^{10}{ }^{11}$ Generally, the curves between temperature and daily respiratory deaths were V-shaped or J-shaped. ${ }^{12}{ }^{13}$ In addition, time-series studies on respiratory mortality have suggested that temperature has lag effects up to 3 weeks after exposure. ${ }^{14}$ As one of the major respiratory diseases, pneumonia has been reported to be influenced by meteorological factors. ${ }^{11}{ }^{15-17}$ However, the relationships varied across areas with different weather patterns and latitudes. In Japan, for example, the case numbers of Mycoplasma pneumoniae pneumonia increased with 
increased average temperature and relative humidity. ${ }^{18}$ Contrarily, neither hot nor cold temperatures had much effect on pneumonia deaths in hot cities in the USA. ${ }^{11}$

Although pneumonia is recognised to result in substantial morbidity and mortality in some developed countries, the potential patterns of associations in other countries remain unclear, whereas the populations of source limited countries may be more sensitive to changes in weather conditions because of their poorer public health infrastructure and vulnerability of the populations. We therefore performed a time-series analysis to estimate the acute effects and time pattern of meteorological factors on hospital admissions for pneumonia. A better understanding of the possible interaction will provide relevant information for developing public health plans and risk assessments in an ambient environment.

\section{MATERIALS AND METHODS}

Data collection

Shanghai is the most populous city in China, located at the eastern tip of the Yangtze River Delta, at latitude $31^{\circ} 14^{\prime} \mathrm{N}$ and longitude $121^{\circ} 29^{\prime} \mathrm{E}$. The city comprises $19 \mathrm{urban} / \mathrm{sub}-$ urban districts and counties, with a total area of $6341 \mathrm{~km}^{2}$, and had a population of over 23 million people by the end of 2010, of which 14 million are registered residents. The city features a moderate subtropical climate, with four distinct seasons and abundant rainfall.

For this analysis, the target population included all registered population living in Shanghai with urban residents' basic medical insurance (hereafter population 1) and urban workers' basic medical insurance (hereafter population 2). Population 1 included children, students and non-employed adults and excluded those with new rural cooperative medical insurance. Population 2 included employees, retirees and other insuranced participants. Daily hospital admissions for pneumonia incurred by the two populations of Shanghai from 1 January 2008 to 31 December 2011 were collected from the Shanghai Municipal Medical Insurance System. All forms of pneumonia coded J12-J18 according to the International Classification of Diseases, the tenth version (ICD-10) were included for the analysis. Daily meteorological data (including mean temperature, relative humidity, precipitation and wind speed) were obtained from the Shanghai Center for Urban Environmental Meteorology. The weather data were measured at a fixed meteorological station located in the Xuhui District of Shanghai. Owing to the probable confounding effects that air pollution and suspended particles may have on temperature and pneumonia, air pollution data (sulfur dioxide $\left(\mathrm{SO}_{2}\right)$, nitrogen dioxide $\left(\mathrm{NO}_{2}\right)$ and particulate matter with particle size below $10 \mu$ (PM10)) were also obtained from the Shanghai Center for Urban Environmental Meteorology.

Patient records/information was de-identified prior to analysis; daily aggregated counts for hospitalisations were calculated and used to implement the final analysis. The authors did not have access to individual patient information prior to data anonymisation and aggregation, and therefore there was no individual interaction with patients in this study.

\section{Statistical methods}

The hospital admissions for pneumonia and meteorological factors were linked by the date and therefore can be analysed with a time-series model. ${ }^{19}$ As the number of daily hospital admissions is a type of low-probability event and follows a Poisson distribution, ${ }^{20}$ a Poisson generalised additive model (GAM) approach was used to explore the association between meteorological factors and hospital admissions for pneumonia.

In order to examine the effect of meteorological factors on hospital admissions for pneumonia, we controlled the potential confounders such as long-term trend, the day of the week (DOW) and air pollutants. We first fitted non-parametric smoothing terms for the trend on days and a dummy variable for DOW. Thereafter, four meteorological factors were introduced into the model to explore the relationship between meteorological factors and hospital admissions for pneumonia. The independent model is described below:

$$
\begin{aligned}
\log \mathrm{E}(\mathrm{Yt})= & \alpha+\mathrm{s}(\text { temperature }, \mathrm{df})+\mathrm{s}(\text { relative humidity }, \mathrm{df}) \\
& +\mathrm{s}(\text { precipitation }, \mathrm{df})+\mathrm{s}(\text { wind speed }, \mathrm{df}) \\
& +\mathrm{s}(\text { time }, \mathrm{df})+\mathrm{DOW}+\mathrm{Z}_{\mathrm{t}}
\end{aligned}
$$

where $\mathrm{E}(\mathrm{Yt})$ denotes the estimated daily hospital admissions for pneumonia counted on day t; $\alpha$ is the intercept; $s()$ denotes a regression spline function for non-linear variables ${ }^{21}$; time is the number of calendar days on day $t ; Z_{t}$ indicates the pollutant concentrations on day $\mathrm{t}$; $\mathrm{df}$ is the degrees of freedom. The partial autocorrelation function $(\mathrm{PACF})^{22}$ was used to select the degrees of freedom of time trends until the absolute values of the sum of PACF for lags up to 30 reached a minimum. Sensitivity analyses were performed to check whether the results were robust to the specification of parameters in the model. We found that the effects were stable when using 4 or 5 degrees of freedom per year for time. In addition, we modified degrees of freedom of the smoothing spline (4-5 df) for the meteorological factors, and the estimates were not changed substantially. These sensitivity analyses resulted in the selection of $4 \mathrm{df}$ per year to control for time trend and $4 \mathrm{df}$ for meteorological factors. For meteorological factors, the selection of degrees of freedom was based on minimising Akaike's information criterion (AIC) ${ }^{23}$

Additionally, we fitted linear terms for the mean temperature in the GAM to explore the log risk of daily hospital admissions for pneumonia associated with a unit increase of mean temperature. On examination of the lag effects of meteorological factors on hospital admissions for pneumonia, we developed two different lag 
structures: single-day lag and multiday average starting from lag 0 . For example, lag 0-1 stands for the 2-day moving average of current and previous day values. Relative risk (RR) refers to the ratio of the probability of an event occurring, while excess risk (ER) is the change in risk of a given activity. We used ER to evaluate the association between daily hospital admissions for pneumonia and a unit change of mean temperature. The value of $E R$ is equal to the value of RR minus one.

We defined 'cold period' as a period of at least five consecutive days with a daily mean temperature below the 25th centile $\left(9.2^{\circ} \mathrm{C}\right)$ and 'hot spot' for admissions as the days with daily pneumonia hospital admissions larger than the 75th centile (85).

Data preparation and analysis were carried out using EXCEL 2010, whereas regression models were fitted using the statistical software R V.3.0.1 by using the mgcv package.

\section{RESULTS}

\section{Data description}

Table 1 summarises the basic statistics for our study. During the study period, totalling 1461 days, 99403 hospital admissions for pneumonia were recorded in Shanghai with a mean of 68 (range, 9-195) per day. During the same time period, the mean daily temperature was $17.3^{\circ} \mathrm{C}$ (range, -3.4 to $35.7^{\circ} \mathrm{C}$ ), reflecting the subtropical climate in Shanghai. A correlation matrix table for the meteorological and air pollution variables was provided in the online supplementary table S2.

\section{Daily hospital admissions and meteorological factors}

Figure 1 shows the exposure-response $(\mathrm{E}-\mathrm{R})$ relationships between daily hospital admissions for pneumonia and mean temperature, relative humidity, precipitation and wind speed, after adjusting for long-term trend, DOW and the air pollutants in the GAM. The relationship between mean temperature and pneumonia hospital admissions followed a V-shape $(\mathrm{p}<0.001$; figure $1 \mathrm{~A})$. The optimum temperature $(\mathrm{OT})$, corresponding to the lowest point in the E-R curve, was about $13^{\circ} \mathrm{C}$. Below the OT, as temperatures increased, the risk of hospital admissions for pneumonia decreased and then reversed the trend above the OT. In addition, relative humidity, precipitation and wind speed had no effects on pneumonia hospital admissions.

\section{Lag effects of temperature on daily hospital admissions}

As there was a V-shaped relationship between mean temperature and hospital admissions for pneumonia, we stratified the data by temperature above ('hot temperature') or below ('cold temperature') the OT. Then linear terms for the daily mean temperature were fitted in GAMs (table 2). In single-day lag structures, associations $(\mathrm{p}<0.01)$ between cold temperature and hospital admissions for pneumonia were found at lag 2-5. The effect from cold temperature appears to be larger than that from hot temperature. The multiday metrics of mean temperature exposure also showed a larger effect of cold temperature than that of hot temperature. The effects by cold temperature peaked at lag 0-6. At lag $0-6$, a $1{ }^{\circ} \mathrm{C}$ decrease in the 7-day moving average of mean temperature corresponded to a $5.34 \%$ (95\% CI $2.04 \%$ to $8.74 \%$ ) increase in hospital admissions for pneumonia. However, no adverse effects of hot temperature were found either in single-day or multiday lag structures.

\section{Effects of cold temperature on different types of people}

Since no adverse effects of hot temperature in hospital admissions for pneumonia were found, we focused further analysis on the association between cold temperature and hospital admissions for pneumonia. The association between hot temperature and hospital admissions for pneumonia was showed in online supplementary table S3. Table 3 shows the different single-day lag effects of cold temperature on different subpopulations. We found the adverse effects of cold temperature in men and women. The effects increased from lag 0 , with peaks in lag 3 for men and in lag 4 for women, and then declined. In age-specific analysis, cold temperature was positively associated with pneumonia hospital admissions and had adverse effects in the categories over age 45 . The OT for people who were aged above 65 was $18^{\circ} \mathrm{C}$, which was larger than that for those younger than 65 .

\begin{tabular}{|c|c|c|c|c|c|c|}
\hline & Mean & SD & Minimum & P25 & P75 & Maximum \\
\hline PHA & 68 & 27 & 9 & 50 & 85 & 195 \\
\hline \multicolumn{7}{|l|}{ Weather condition } \\
\hline Mean temperature $\left({ }^{\circ} \mathrm{C}\right)$ & 17.3 & 9.2 & -3.4 & 9.3 & 25.1 & 35.7 \\
\hline Relative humidity (\%) & 69 & 13 & 23 & 61 & 79 & 95 \\
\hline Precipitation (mm) & 30.9 & 94.5 & 0.0 & 0.0 & 12.0 & 1284.0 \\
\hline Wind speed (m/s) & 2.9 & 1.0 & 0.8 & 2.2 & 3.5 & 7.3 \\
\hline \multicolumn{7}{|l|}{ Air pollution } \\
\hline $\mathrm{SO}_{2}\left(\mu \mathrm{g} / \mathrm{m}^{3}\right)$ & 36 & 20 & 11 & 22 & 43 & 147 \\
\hline $\mathrm{NO}_{2}\left(\mu \mathrm{g} / \mathrm{m}^{3}\right)$ & 54 & 21 & 12 & 39 & 65 & 142 \\
\hline $\mathrm{PM}_{10}\left(\mu \mathrm{g} / \mathrm{m}^{3}\right)$ & 79 & 53 & 12 & 45 & 100 & 599 \\
\hline
\end{tabular}



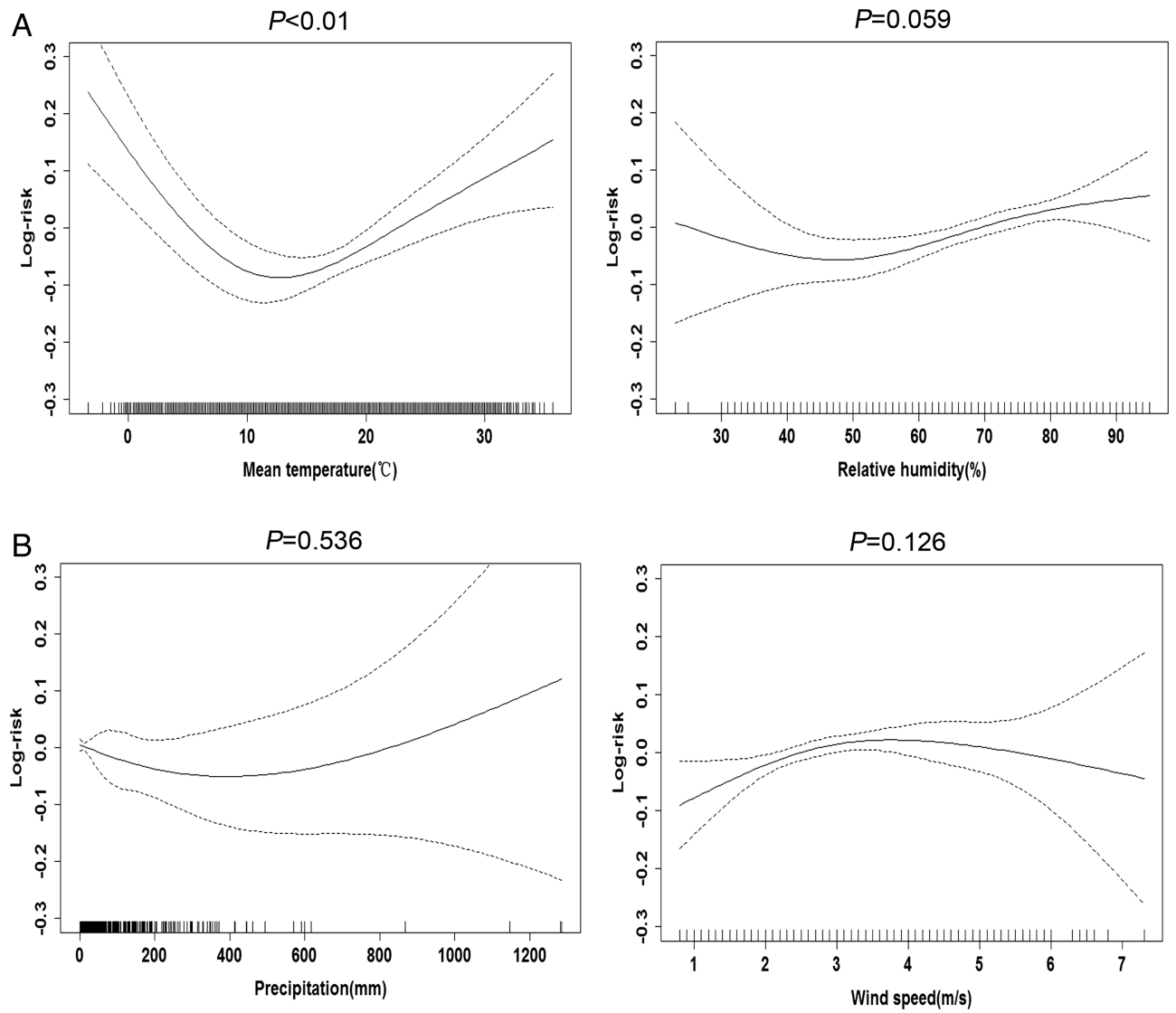

Figure 1 Smoothing plots of meteorological factors against hospital admissions for pneumonia. (A) mean temperature at lag 4; (B) relative humidity at lag 0; (C) precipitation at lag 0; and (D) wind speed at lag 0 . The solid lines indicate the estimated mean percentage of change in pneumonia hospital admissions, the dotted lines represent $95 \% \mathrm{Cl}$ and log-risk represents log (RR).

\begin{tabular}{|c|c|c|c|c|c|}
\hline \multirow[b]{2}{*}{ Lag (days)† } & \multirow[b]{2}{*}{ ОТ $\left({ }^{\circ} \mathrm{C}\right)$} & \multicolumn{2}{|c|}{ Cold temperature } & \multicolumn{2}{|c|}{ Hot temperature } \\
\hline & & $\overline{\mathrm{ER}}$ (\%) & $95 \% \mathrm{Cl}$ & $\overline{\text { ER (\%) }}$ & $95 \% \mathrm{Cl}$ \\
\hline Single day & 13 & & & & \\
\hline 0 & & -2.05 & -4.78 to 0.61 & 0.80 & -0.90 to 2.51 \\
\hline 1 & & 0.43 & -2.07 to 3.01 & 0.41 & -1.26 to 2.11 \\
\hline 2 & & $3.06^{*}$ & 0.72 to 5.47 & 0.04 & -1.62 to 1.74 \\
\hline 3 & & $4.85^{\star \star}$ & 2.65 to 7.09 & 0.37 & -1.28 to 2.04 \\
\hline 4 & & $4.88^{\star \star}$ & 2.71 to 7.09 & 1.28 & -0.36 to 2.96 \\
\hline 5 & & $2.85^{\star}$ & 0.65 to 5.10 & 1.16 & -0.48 to 2.83 \\
\hline 6 & & 1.39 & -0.81 to 3.64 & 1.21 & -0.41 to 2.86 \\
\hline Multiday & 13 & & & & \\
\hline $0-1$ & & 0.03 & -2.62 to 2.75 & 0.13 & -1.66 to 1.96 \\
\hline $0-2$ & & 1.57 & -1.26 to 4.48 & -0.08 & -1.96 to 1.83 \\
\hline $0-3$ & & $3.67^{\star}$ & 0.84 to 6.59 & -0.38 & -2.39 to 1.67 \\
\hline $0-4$ & & $4.88^{\star \star}$ & 1.89 to 7.95 & -0.42 & -2.53 to 1.75 \\
\hline $0-5$ & & $5.21^{\star \star}$ & 2.14 to 8.36 & -0.62 & -2.93 to 1.75 \\
\hline $0-6$ & & $5.34^{\star *}$ & 2.04 to 8.74 & -0.94 & -3.42 to 1.60 \\
\hline $0-7$ & & $5.10^{\star \star}$ & 1.53 to 8.79 & -0.48 & -3.22 to 2.33 \\
\hline $0-8$ & & $4.48^{\star}$ & 0.72 to 8.37 & -0.67 & -3.47 to 2.21 \\
\hline $0-9$ & & $4.01^{*}$ & 0.03 to 8.15 & 0.15 & -2.81 to 3.20 \\
\hline $0-10$ & & 1.43 & -0.26 to 3.16 & 1.02 & -0.52 to 2.59 \\
\hline
\end{tabular}

${ }^{*} p<0.05 .{ }^{* *} p<0.01$.

†Lag 0-6: single-day lag from 0 to 6; lag $0-1$ to lag $0-10$ : multiday average of mean temperature (lag 0-1 means 2 -day moving average of current and previous day values).

†ER means excess risk, ER=relative risk (RR)-1. 


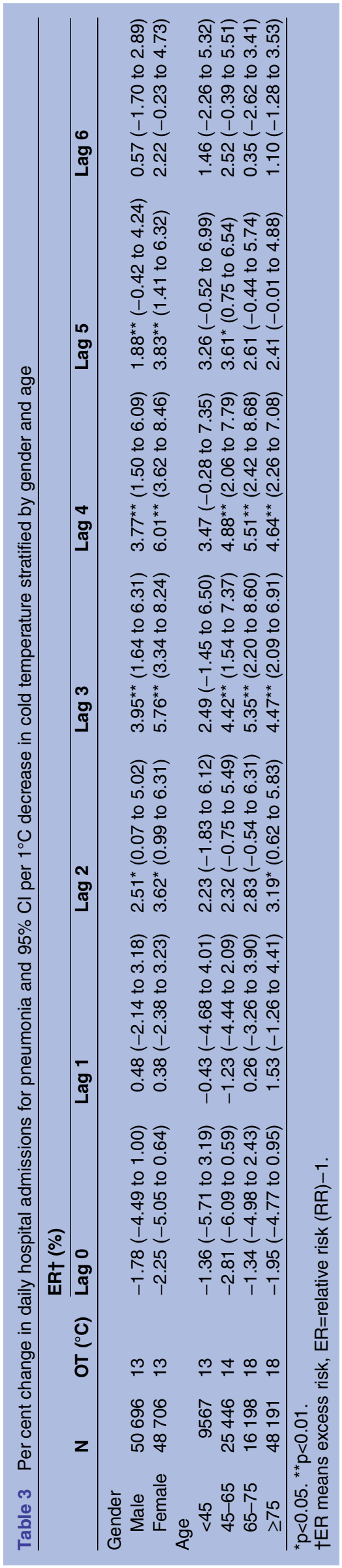

Figure 2 shows the single-day lag effects of cold temperature on different subpopulations. The effects reached a maximum in lag 3 on population 1 while in lag 4 on population 2 . A $1{ }^{\circ} \mathrm{C}$ decrease in cold temperature corresponded to a $4.87 \%$ (95\% CI $2.67 \%$ to $7.12 \%$ ) increase in hospital admissions for pneumonia on population 2 in lag 4 while it was $4.13 \%$ (95\% CI $0.77 \%$ to $7.60 \%)$ on population 1 in lag 3 . The effects on population 2 appear to be larger and more persistent than those on population 1 .

\section{Effects of cold period on pneumonia hospital admissions}

Since cold temperature had large and persistent effects on pneumonia hospital admissions, we conducted a further analysis of cold temperature effects.

Figure 3 shows that pneumonia hospital admissions varied with the daily mean temperature, while the cold period is related to hot spots for pneumonia hospital admissions. A $2 \times 2$ table to show the association between cold period and hot spots was provided in online supplementary table S1. We used the cold period as a binary classification variable and fitted it in the GAM. The result showed that hospital admissions for pneumonia increased by $15.99 \%$ (95\% CI $0.06 \%$ to $34.46 \%$ ) in the cold period.

\section{DISCUSSION}

This time-series analysis showed that ambient temperature was associated with hospital admissions for pneumonia, while relative humidity, precipitation and wind speed did not show the same. To the best of our knowledge, this is the first to report the effects of meteorological factors on hospital admissions for pneumonia in China.

Generally, temperature appears as V-shaped, U-shaped or J-shaped variations with mortality or morbidity, with OT corresponding to the lowest point in the temperature mortality curve. ${ }^{8}{ }^{24}$ The present study showed a V-shaped curve in the relationship between mean temperature and hospital admissions for pneumonia. Although the observation is consistent with the reported studies, we observed a different OT $\left(13^{\circ} \mathrm{C}\right)$ in Shanghai, in comparison with $20^{\circ} \mathrm{C}$ in $\mathrm{St} \mathrm{Paul},{ }^{25} 16.5^{\circ} \mathrm{C}$ in the Netherlands and $19^{\circ} \mathrm{C}$ in London. ${ }^{26}$ We found that, similar to the Beijing study, ${ }^{27}$ cold temperature presented larger effects. Other studies report that the peaks of the respiratory syncytial virus and invasive pneumococcal disease were inversely correlated with temperature $^{28} 29$ and that the cold temperature was favourable to the spread of the influenza virus, ${ }^{30}$ which might partly explain the association between cold temperature and hospital admissions for pneumonia.

We developed two different lag structures to examine the health effects of temperature. Adverse effects were observed in single-day and multiday lag effects models for cold temperature, while neither single-day nor multiday lag effects were found from hot temperature. These 
Figure 2 Per cent change in daily hospital admissions for pneumonia and $95 \% \mathrm{Cls}$ per $1^{\circ} \mathrm{C}$ decrease in cold temperature using a single-day lag structure by a different subpopulation.

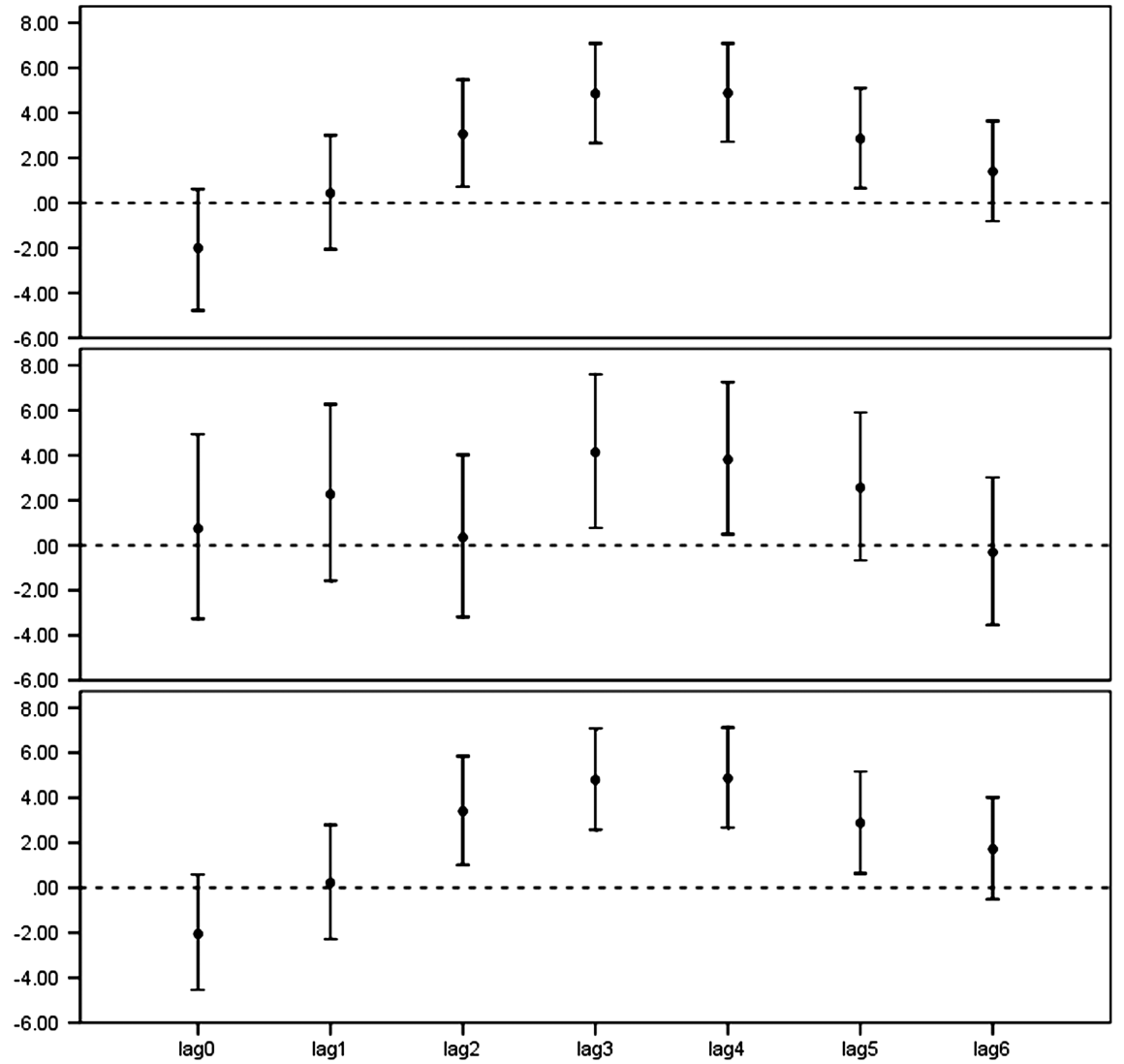

findings were slightly different from other studies on morbidity. For example, Braga et al ${ }^{11}$ described that the effect of cold temperatures persisted for days, whereas the effect of high temperatures was restricted to the day or the day before. Yu et $a l^{31}$ demonstrated that cold temperature had a lag time of 21 days, while hot temperature appears to exhibit acute effects in the short term.

Given the established importance of seasonal variation in mortality and morbidity excesses of respiratory diseases, $^{32}$ several research studies have reported particularly on the relationship between extremely cold climatic episodes and mortality and morbidity, noting that the tendency for a winter mortality increased after the occurrence of cold spells. ${ }^{33}$ However, there is neither a uniform and agreed definition of a cold spell ${ }^{34}$ nor a precise definition of the period for which such events should be studied. Our criterion for identifying a cold period was to combine time and temperature thresholds, which is similar to that of other studies. ${ }^{35} 36$ We found that there was a $15.99 \%$ increase in
Figure 3 Daily mean temperature and daily pneumonia hospital admissions. Cold period means a period of at least five consecutive days with a daily mean temperature below the 25th centile $\left(9.2^{\circ} \mathrm{C}\right)$; 'hot spot' for admissions means the day with daily pneumonia hospital admissions larger than the 75th centile (85).

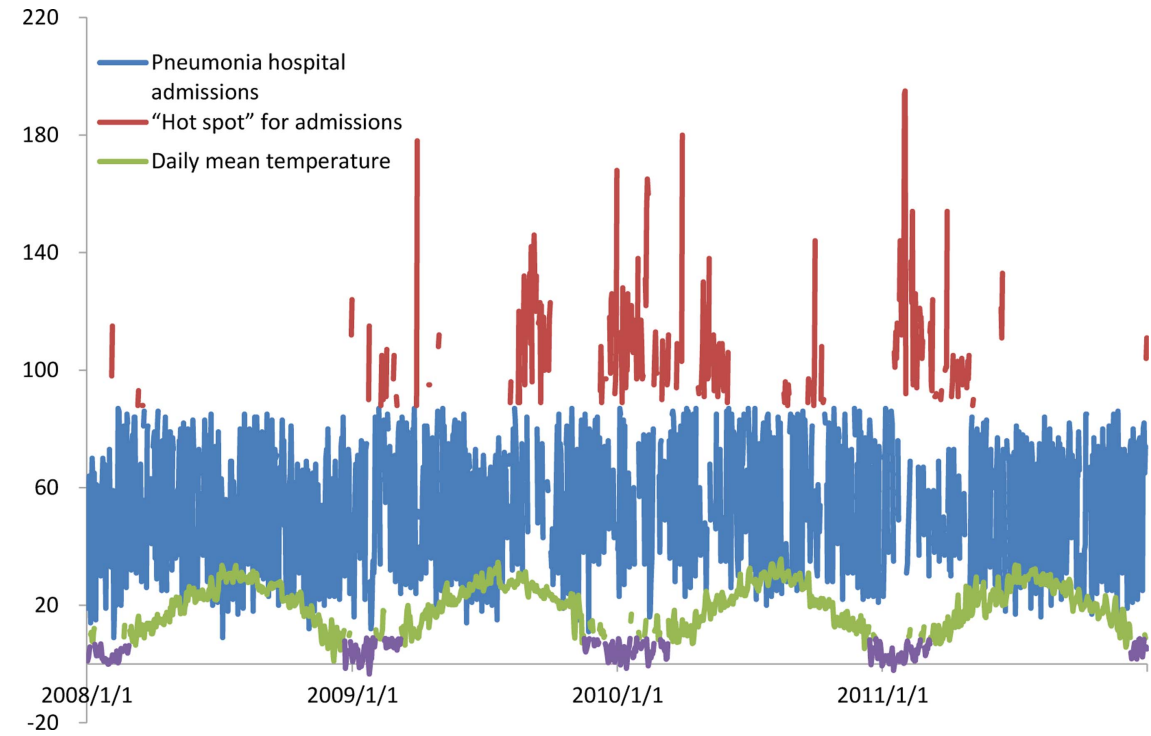


pneumonia hospital admissions in the cold period. Further studies are needed to explore if the cold temperature effects on pneumonia are due to the cold temperature itself or a result of other factors.

The effects of cold temperature on different populations were observed. The effect of cold temperature on population 2 was found to be larger and more persistent than that on population 1. Adverse effects of pneumonia hospitalisations on population 2 were larger (ER increased by $0.67 \%$ and $1.06 \%$ in lag 3 and lag 4 , respectively) than those on population 1 . Population 2 included employees and retirees while population 1 was mostly made up of non-employed adults and students. Employees have more work pressure and have fewer opportunities to exercise, which might weaken their immunity; the elderly people are usually more susceptible to heat-related or cold-related health risks. ${ }^{37} 38$ The magnitude of the effects of temperature varied with gender and age. The OT for $\geq 65$ age groups was higher than that for $<65$ age groups, indicating that the elderly people had increased vulnerability to cold weather for pneumonia. Cold temperature only showed its effect on people older than 45. For residents in this age group, the ability to regulate body temperatures is reduced, and sweating thresholds are generally elevated in comparison with younger people. ${ }^{39}$

Influenza epidemics, which generally occur in the cold weather, have been accounted for as confounders in some studies. ${ }^{40}$ Owing to the lack of reliable data, we did not include the influenza epidemics as a control factor. However, the smooth function of time should have eliminated most of such residual secular effects and there is no reason to expect an association of influenza with temperature (after controlling for the time trend). In addition, many other studies have not included influenza as a confounder. 812

Our study has several limitations. First, we used the available outdoor monitoring data of ambient meteorological factors derived from a monitoring station rather than measures of personal exposure. This was expected to result in exposure misclassification. Second, our study only contained hospitalisations for pneumonia, but excluded less severe cases. Therefore, the effects of the meteorological factors on hospital admissions of pneumonia that we observed may not be applicable to the effects on the overall situation of pneumonia. Third, the findings of this study should be treated cautiously when generalised to other locations, particularly in places with different climates. In addition, the influence of ozone was not controlled for, because the data of ozone were not available.

\section{CONCLUSION}

We observed associations between meteorological factors and daily pneumonia hospital admissions in Shanghai. Cold temperature presented larger and more persistent effects and the magnitude of these effects of temperature varied with gender and age. Cold period had adverse effects on pneumonia hospital admissions. Prevention programmes may be needed to reduce the impact of cold temperature such as developing a weather warning system within a wide public health context.

\section{Author affiliations}

${ }^{1}$ School of Public Health and Key Laboratory of Public Health Safety (Ministry of Education), Fudan University, Shanghai, China

${ }^{2}$ Fudan Tyndall Centre, Shanghai, China

${ }^{3}$ Shanghai Center for Urban Environmental Meteorology, Shanghai, China ${ }^{4}$ Shanghai Key Laboratory of Meteorology and Health, Shanghai, China

${ }^{5}$ Health and Climate Foundation, Washington DC, USA

Contributors JX, LP and XY provided and organised the data; YL, YZ and RC conducted the study and performed the data analysis, and $L Y$ drafted the manuscript; WW, HK and DR reviewed and edited the manuscript, and WW conceived the study and contributed to the study design. All authors read and approved the final manuscript.

Funding This study was funded by the Global Environment Change Research in Fudan University (Grant No. EZH1829007/003), the Chinese Meteorological Administration (Grant No. GYHY201206027), the Scientific Innovation Action Plan by the Science and Technology Commission of Shanghai Municipality (Grant No. 13511504906) and the programme of Key Discipline Development of Public Health of Shanghai (Grant No. 12GWZX0101).

\section{Competing interests None.}

Provenance and peer review Not commissioned; externally peer reviewed.

Data sharing statement No additional data are available.

Open Access This is an Open Access article distributed in accordance with the Creative Commons Attribution Non Commercial (CC BY-NC 3.0) license, which permits others to distribute, remix, adapt, build upon this work noncommercially, and license their derivative works on different terms, provided the original work is properly cited and the use is non-commercial. See: http:// creativecommons.org/licenses/by-nc/3.0/

\section{REFERENCES}

1. World Health Organization. The top 10 causes of death. 2008. http://www.who.int/mediacentre/factsheets/fs310/en/ (accessed 19 Jan 2010).

2. Rudan I, O'Brien KL, Nair H, et al. Epidemiology and etiology of childhood pneumonia in 2010: estimates of incidence, severe morbidity, mortality, underlying risk factors and causative pathogens for 192 countries. J Glob Health 2013;3:10401.

3. Mathers C, Bernard C, Moesgaard Iburg K. WHO. Global burden of disease in 2002: data sources, methods and results. Ref Type: Generic

4. Polverino E, Torres Marti A. Community-acquired pneumonia. Minerva Anestesiol. 2011;77:196-211.

5. Guan X, Silk BJ, Li W, et al. Pneumonia incidence and mortality in Mainland China: systematic review of Chinese and English literature, 1985-2008. PLOS ONE 2010;5:e11721.

6. Li-xian HE, Xue-hua C. Contentions on the pathogenic spectrum of community-acquired pneumonia and the first experimental application of antibiotic agents. Chin J Pract Intern Med 2007;27:110-13.

7. Shea KM, Truckner RT, Weber RW, et al. Climate change and allergic disease. J Allergy Clin Immunol 2008;122:443-53; quiz 54-5.

8. Curriero FC, Heiner KS, Samet JM, et al. Temperature and mortality in 11 cities of the eastern United States. Am J Epidemiol 2002;155:80-7.

9. Haines A, McMichael AJ, Epstein PR. Environment and health: 2. Global climate change and health. CMAJ 2000;163:729-34.

10. Braga AL, Zanobetti A, Schwartz J. The time course of weather-related deaths. Epidemiology 2001;12:662-7.

11. Braga AL, Zanobetti A, Schwartz J. The effect of weather on respiratory and cardiovascular deaths in 12 U.S. cities. Environ Health Perspect 2002;110:859-63.

12. Farajzadeh $M$, Darand $M$. Analyzing the influence of air temperature on the cardiovascular, respiratory and stroke mortality in Tehran. Iran $J$ Environ Healt 2009;6:261-70. 
13. Liu L, Breitner S, Pan X, et al. Associations between air temperature and cardio-respiratory mortality in the urban area of Beijing, China: a time-series analysis. Environ Health 2011;10:51.

14. Huynen MM, Martens $\mathrm{P}$, Schram D, et al. The impact of heat waves and cold spells on mortality rates in the Dutch population. Environ Health Perspect 2001;109:463-70.

15. Ye Y, Zulu E, Mutisya M, et al. Seasonal pattern of pneumonia mortality among under-five children in Nairobi's informal settlements. Am J Trop Med Hyg 2009;81:770-5.

16. Egondi T, Kyobutungi C, Kovats $\mathrm{S}$, et al. Time-series analysis of weather and mortality patterns in Nairobi's informal settlements. Glob Health Action 2012;5:23-32.

17. Lim $\mathrm{YH}$, Hong $\mathrm{YC}, \mathrm{Kim} \mathrm{H}$. Effects of diurnal temperature range on cardiovascular and respiratory hospital admissions in Korea. Sci Total Environ 2012;417-418:55-60.

18. Onozuka D, Hashizume M, Hagihara A. Impact of weather factors on Mycoplasma pneumoniae pneumonia. Thorax 2009;64:507-11.

19. Zeger SL, Irizarry R, Peng RD. On time series analysis of public health and biomedical data. Annu Rev Public Health 2006;27:57-79.

20. Cao J, Li W, Tan J, et al. Association of ambient air pollution with hospital outpatient and emergency room visits in Shanghai, China. Sci Total Environ 2009;407:5531-6.

21. Guo $\mathrm{Y}$, Barnett $\mathrm{AG}, \mathrm{Yu} \mathrm{W}$, et al. A large change in temperature between neighbouring days increases the risk of mortality. PLOS ONE 2011;6:e16511.

22. $\mathrm{Kan} \mathrm{H}$, London $\mathrm{SJ}$, Chen $\mathrm{H}$, et al. Diurnal temperature range and daily mortality in Shanghai, China. Environ Res 2007;103:424-31.

23. Hastie T, Tibshirani R. Generalized additive models for medical research. Stat Methods Med Res 1995;4:187-96.

24. Kan HD, Jia J, Chen BH. Temperature and daily mortality in Shanghai: a time-series study. Biomed Environ Sci 2003;16:133-9.

25. Gouveia N, Hajat S, Armstrong B. Socioeconomic differentials in the temperature-mortality relationship in Sao Paulo, Brazil. Int $J$ Epidemiol 2003;32:390-7.

26. Patz JA, Campbell-Lendrum D, Holloway T, et al. Impact of regional climate change on human health. Nature 2005;438:310-17.

27. Mo YZ, Zheng YA, Tao H, et al. [Relationship between daily mean temperature and emergency department visits for respiratory diseases: a time-series analysis]. Beijing Da Xue Xue Bao 2012;44:416-20.

28. Yusuf S, Piedimonte $\mathrm{G}$, Auais $\mathrm{A}$, et al. The relationship of meteorological conditions to the epidemic activity of respiratory syncytial virus. Epidemiol Infect 2007;135:1077-90.

29. Murdoch DR, Jennings LC. Association of respiratory virus activity and environmental factors with the incidence of invasive pneumococcal disease. $J$ Infect 2009;58:37-46.

30. Lowen AC, Mubareka S, Steel J, et al. Influenza virus transmission is dependent on relative humidity and temperature. PLOS Pathog 2007;3:1470-6.

31. Yu W, Mengersen K, Hu W, et al. Assessing the relationship between global warming and mortality: lag effects of temperature fluctuations by age and mortality categories. Environ Pollut 2011;159:1789-93.

32. Donaldson GC, Goldring JJ, Wedzicha JA. Influence of season on exacerbation characteristics in patients with COPD. Chest 2012;141:94-100.

33. Revich B, Shaposhnikov D. Excess mortality during heat waves and cold spells in Moscow, Russia. Occup Environ Med 2008;65:691-6.

34. Kysely J, Pokorna L, Kyncl J, et al. Excess cardiovascular mortality associated with cold spells in the Czech Republic. BMC Public Health 2009;9:19.

35. Ma W, Yang C, Chu C, et al. The impact of the 2008 cold spell on mortality in Shanghai, China. Int J Biometeorol 2013;57:179-84.

36. Monteiro A, Carvalho V, Góis J, et al. Use of "Cold Spell" indices to quantify excess chronic obstructive pulmonary disease (COPD) morbidity during winter (November to March 2000-2007): case study in Porto. Int J Biometeorol 2013:57:857-70.

37. Ye X, Wolff R, Yu W, et al. Ambient temperature and morbidity: a review of epidemiological evidence. Environ Health Perspect 2012;120:19-28.

38. Yu W, Mengersen $\mathrm{K}$, Wang $\mathrm{X}$, et al. Daily average temperature and mortality among the elderly: a meta-analysis and systematic review of epidemiological evidence. Int J Biometeorol 2012;56:569-81.

39. Kenney WL, Hodgson JL. Heat tolerance, thermoregulation and aging. Sports Med 1987:4:446-56.

40. Armstrong B. Models for the relationship between ambient temperature and daily mortality. Epidemiology 2006;17:624-31. 